\title{
Scaffolding Oral Fluency Mediating the Target Language in ELT to Tertiary-Level Students: A Follow-up Scheme
}

\section{Mohammed Abdulgalil Abugohar}

English Language Department, Al-Ghad International Colleges for Applied Medical Sciences, Saudi Arabia,modyjau@yahoo.com

\section{Dalal Alfadhil Attaher Salheen}

Department of English, Faculty of Arts, Bani Walid University, Libya, \& Department of English, Faculty of Modern Languages and Communication, Universiti Putra Malaysia (UPM), Malaysia, dalal_salhin@yahoo.com

\section{Baderaddin Yassin}

English Language Center, Al-Ghad International Colleges for Applied Medical Sciences, Riyadh, Saudi Arabia, byassin@gc.edu.sa

\section{Hadeel A Saed}

Applied Science Private University, Amman, Jordan, hadeel_99@yahoo.com

\section{Kamariah Yunus}

Faculty of Languages and Communication, Universiti Sultan Zainal Abidin (UniSZA), Terengganu, Malaysia, kamariah@unisza.edu.my

One of the tasks for language teachers is to create an interactive environment to help learners communicate globally in the 21 st century. Employing a case-study design, this research is aimed to explore how far using the target language (L2), as the main language of classroom interaction, can affect students' oral fluency through the technique of Challenge, Action, and Result. Attempting to accomplish the assigned purpose, this study was carried out for four weeks to obtain qualitative data using an observation checklist in following 31 students at the university level. Through this paper, we share our experience to provide instructors in higher education with one of the solutions to learners' oral inefficiency. The study findings proved that there was a remarkably positive influence of mediating English in classroom interaction on improving learners' fluency. Implications of the research are further discussed in the conclusion section.

Keywords: oral fluency, mediating target language (L2), tertiary-level students, English Language Teaching (ELT), follow-up scheme

Citation: Abugohar, M. A., Salheen, D. A. A., Yassin, B., Saed, H. A., \& Yunus, K. (2020). Scaffolding Oral Fluency Mediating the Target Language in ELT to Tertiary-Level Students: A Followup Scheme. International Journal of Instruction, 13(4), 331-346. https://doi.org/10.29333/iji.2020.13421a 


\section{INTRODUCTION}

Developing a good mastery of communicative skills is the main target of teaching and learning English as a Second Language (ESL) and English as a Foreign Language (EFL). Communicative skills are the different media through which a person can express himself, contact with others, and comprehensibly send and receive a message. In the Communicative Language Teaching approach (CLT), communication in the target language constitutes a pivotal part of the classroom practices (Littlewood, 1981). However, mastering communicative skills is not a day-and-night matter. Fahad (2012) asserts that "Oral proficiency and communicative skills have always been a benchmark of ELT all over the world" (p. 3). One of the most challenging features of English is how to speak fluently; and hence, improving this skill is supposed to be given full care by English teachers in general and by the ones working in higher education as well.

There are many factors that should be taken into account when it comes to speaking proficiency. Among the factors that together significantly enhance the task of oral production in a foreign language are the lexical knowledge, accuracy, intonation and accent, fluency, and pronunciation (Yavari \& Shafiee, 2019). In other words, if someone wants to learn how to swim, which is better- to read a book about swimming or to simply drop himself into a swimming pool? That is the very question- 'How can a language teacher ask students to speak in English, whereas he, himself, speaks in the native language (L1) in most of the English classroom sessions?' A lot of scholars have been advocating using the target language in classrooms as much as possible. Macaro (1997) confirms that language learners are expected to use and respond to the target language, and to use their mother tongue only when necessary, i.e., when comparing English and the target language in specific structural aspects. Therefore, this study attempted to shed light on the importance of using English as a prescribed medium of instruction in language classrooms.

\section{LITERATURE REVIEW}

Oral production, or speaking performance, is a popular field for researchers who have assessed it from various angles. Consequently, several measures are used as indicators of the actual level of oral performance (Ellis \& Barkhuizen, 2009). Having various speaking aspects resulted in a growing interest among teachers and researchers in understanding how language development occurs through situated interaction in classrooms, not in laboratories (Ohta, 2009, p. 50). The present study's theoretical framework is based on second language acquisition-learning theories. A wide range of research has been done concerning speaking skills and using the target language inside the classroom. It has been concluded that the more English-like the teaching environment is, the more opportunities learners have for speaking freely and practising more and more English. Vygotsky (1962) argues that children learn through social interaction. Thus, language learners can construct their language awareness and knowledge through other people, and across the interaction with their counterparts as well as teachers. Adults/teachers work actively with students in the Zone of Proximal Development (ZPD) to scaffold learners' language skills. This process results in promoting the language skills of the target learners. Oral fluency can be seen as one of 
the prominent skills that can be enhanced to a large extent through interaction and practices. One of the channels for that interaction is the language used as a medium of instruction in classrooms. This is due to the role language plays in mediated learning, which is the central concept in sociocultural theory, and practice is the means through which speaking fluency is scaffolded.

In his book entitled 'Using the Target Language', Dickson (1996, p. 17) advocates using the target language (TL/L2) in the classroom. He argues that it is the most appropriate for learners to learn through the use of the TL actively. He also says that opportunities for learners to interact through conversation in the classroom are essential for learning, and that, therefore, much attention should be paid to students' use of the TL (L2), and to teachers' use as well. Here lie the essential roles played by ESL/EFL teachers to adhere to speaking English during classroom instruction and discussions.

In addition, when an ESL/EFL teacher sticks to speaking English in language classrooms at a comprehensible level that is asserted by Krashen (2009), this is expected to result in creating a natural discourse for language practice which is entirely consistent with the five hypotheses of the language acquisition (Krashen \& Terrell, 1995). It is now well viewed that communication serves as one of the primary ways in which learners obtain data with which to construct their interlanguages (Ellis, 2009; Hatch, 1978; Van Lier, 1988). In an environment where teachers adhere to interact and communicate with their students in the target language, students find themselves motivated and, at the same time, challenged to speak in English with each other as well as with their teacher. Teachers should provide a role model by using the target language (L2) in classrooms instead of the native language (L1).

\section{Relevant Studies}

Kadi and Madini (2019) investigated the causes that lie behind Saudi students' unwillingness to communicate in the EFL classroom. Adopting a mixed-method approach with a sample of 136 Saudi female preparatory year students in the English Language Institute (ELI) at King Abdulaziz University (KAU), their study employed two instruments- an online questionnaire with 126 participants and semi-structured interviews with 10 participants. The results revealed that the unwillingness to communicate in L2 stemmed from multiple causes. Among those factors are learners' fear of making mistakes, low language proficiency, fear of negative evaluation, shyness, lack of self-confidence, and some inefficient teaching practices during which learners have limited exposure to the target language.

In his study, Albino (2017) assessed EFL learners' improvement in terms of speaking fluency adopting a Task-Based Language Teaching (TBLT) approach used with ninthgrade learners at PUNIV-Cazenga, a high school in Luanda. In a case study design, he used picture-description tasks. To examine the impact of the intervention applied for 8 weeks, learners' speeches were audio-recorded prior to and after the treatment. The findings revealed that students' performance improved in terms of oral fluency by maximizing their speed of speech production, increasing grammatical accuracy, elaborating their utterances, and developing interactional language. 
Barriga and Briesmaster (2017) carried out action research at a technical university in Chile. They investigated the effect of using the $3 / 2 / 1$ technique on tertiary students' oral fluency. Collecting quantitative and qualitative data, the results showed that after the implementation of the $3 / 2 / 1$ technique, there was a small improvement in participants' speech in terms of words per minute (WPM) and pauses made. The majority of the participants found this technique useful for their development of fluency.

Khati (2011) conducted a study discussing why some EFL teachers use the mother tongue inside language classrooms. He found out that most teachers and students overuse their mother tongue, in his case, most probably the Nepali in English as a Foreign Language (EFL) classroom particularly in government-aided (Nepali medium) schools of Nepal. This, as a result, minimized the students' exposure to English.

Another thesis, written by Fahad (2012), asserted the importance of enhancing learners' communicative skills through classroom interaction in Iraqi EFL classes. He concluded that in Iraq, the level of EFL learners has always been unsatisfactory because of the apparent lack of exposure to the target language in Iraqi classrooms and the focus which has always been on the grammar or form.

In his paper, Guilloteaux (2008) investigated some of the effective classroom managers in South Korean EFL classrooms. He found out that classroom management in language teaching can be broadly depicted in which language teachers adhere to creating and maintaining a classroom environment that can enhance optimal learning of the target language while promoting the development of student self-control. Therefore, managing a language classroom requires overseeing all classroom activities, including language learning activities, social interactions, and student performance. On the contrary, Qadumi (2007) developed a study to determine English language teachers' attitudes toward using Arabic in EFL classrooms in one of the Northern Districts of Palestine, namely, Qalqilya. After he had explained that the problem of his study is controversial, he showed the results to conclude that using L1 or mother tongue can be tolerated, to an extent, inside the EFL classroom according to specific criteria.

Based on the body of literature, it would be useful to shed light on the current issue to study. From the researchers' experience, it can be said that most language teachers do overuse the mother tongue beyond all extents. Nonetheless, it is critical for language teachers and learners to depend mainly on using the target language, English, in language classrooms. Herein lies the crux of the gap that needs more in-depth investigation. There is a pressing need to offer various techniques to help teachers scaffold their learners' speaking skills, among those techniques is the 3 -step technique of Challenge, Action, and Result (CAR) that is implemented in the current study mediating the target language (L2), aiming at boosting adult students' oral fluency.

\section{Speaking Fluency}

A fluent speaker of a language is defined as the person who can express himself easily and naturally, producing language in real-time without undue pausing or unnatural hesitations (Bohlke, 2014; Ellis \& Barkhuizen, 2009). Fluency prioritises meaning and 
semantic over form in a way to ensure having the task done and the message fully understood.

Fluency is defined as how fast and how much a learner speaks without dysfluency markers (e.g., functionless repetitions, self-corrections, and false starts) in "coping with real-time processing" (Wolfe-Quintero et al., 1998, p. 14). Lennon (1990) argues that fluency measures have two categories: "temporal measures and measures of a degree of freedom from various dysfluency markers" (p. 403).

Language learners struggle against a group of factors that are reflected in obstacles to the teaching of English as Foreign Language (TEFL), leading to restricting the students' oral production in general and speaking fluency in particular. These factors are summarized in Figure 1.

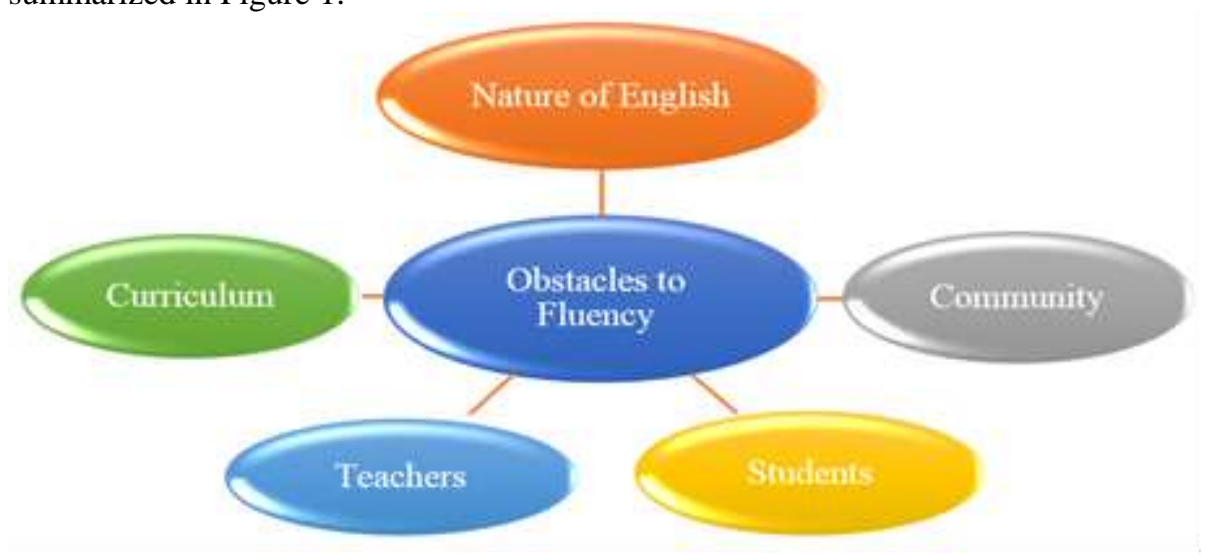

Figure 1

Obstacles to Fluency

A lot of factors working together are attributed to the difficulty of mastering speaking skills in general and fluency in specific for language learners, as shown in Figure 1. The nature of English as a language and its distinct features can be the first category which has then been compared with L1 widening the gap between L1 and L2. The second category refers to the lack of the community in which the EFL learners can possibly practise their speaking. The third group includes the syllabus design and how it directs the teaching and learning process, speaking in particular. Finally, the last two groups consist of factors related to teachers' and learners' practices, perceptions, and tendencies.

\section{Significance of the Study}

Cook (2006) states that the learner mainly "needs to encounter the language in order to learn it. One of the functions of teaching is to provide samples of the L2 for language learners. The argument suggests that the teacher can maximise the provision of useful L2 examples by avoiding the L1."

Since this study highlights the value of teachers' adherence to using English inside classrooms, it is supposed to be of great value for EFL teachers as it sheds more light on 
the teaching medium that can make learning more effective and create a semi-native environment. Also, learners find themselves practise listening to and speaking English more often. All of these are expected to improve university students' speaking skills. In addition, the study can guide syllabus designers to design more speaking activities for teachers and learners to practise. As confirmed by the Sociocultural Constructivist Theory (SCT), the primary means of mediation is verbal interaction using language (Ellis, 2012).

\section{METHOD}

This study is a part of a whole project that involved several groups of authorship. In the first stage of the project, English language teachers' attention was attracted to using extracurricular activities as remedial work for fostering speaking skills of high school students (Yusof \& Abugohar, 2017). Besides, Abugohar and Yunus (2018) concluded that many problems were hindering EFL learners form mastering oral skills. Then, in the second stage, tertiary learners' language needs were analysed, revealing that speaking was the most crucial, challenging and critical skill for them (Abugohar, Al-Hnifat, AlSmadi, Rashid \& Yunus, 2019). Testing solutions offered by modern technology for that issue of oral inferiority, teachers' perceptions and practices of smartphone applications, therefore, were investigated (Abugohar, Yunus \& Rashid, 2019), and, at the same time, the properties of handheld technologies were elaborately reviewed (Abugohar, Yunus, Rabab'ah \& Ahmed, 2019). Currently, the project is proceeding with identifying several remedies; one of these is using L2 as the main channel of classroom interaction and instruction. The current project is exploring the effects of communicating through L2 on learners' participation, interaction, speaking confidence, and speaking fluency. In this paper, however, the focus is on one aspect of classroom interaction using the target language- scaffolding university students' speaking fluency.

\section{Research Design}

The present study adopted the case-based qualitative research approach since we found it the most appropriate in capturing the growing picture and giving in-depth exploration (Flick, 2014) when it comes to investigating the aspects of human interaction (studentstudent, and student-teacher) within language classrooms. Case-study research involves the study of an issue explored through one or more cases within a bounded system, giving in-depth exploration of the particularity and complexity of the studied case or cases (Creswell, 2007; Dörnyei, 2011). The data for the current study were collected through close observation of classroom practices and interaction in order to provide a full understanding of the situation and explore strategies that can help in enhancing the interaction in the target language tapping on the issue studied- the influence of the classroom language used in instruction on participants' speaking fluency.

To attain the above-stated objective, a group of 31 adult EFL learners was purposively selected based on their achievement in previous speaking exams that were administered by their institution. Only learners with low scores in previous assessments were assigned for the present study. A 3-step CAR technique of 'Challenge, ' 'Action,' and 'Result' was applied. First, learners' ZPD was challenged when the L2 dominated as the only medium 
of the teaching/learning context. Then, the action was carried out forcing language learners to struggle using the target language of English in order to keep communicating in the classroom. Finally, the third step of the technique, Result, was taken to assess the progress in oral fluency of the target participants whose performance was followed for four weeks to collect the data.

Some procedures were followed to maintain the validity of the tool used and the trustworthiness of the findings. First, the checklist was self-developed by the researcher, and its validity was ensured by consulting experts in the field of TEFL. To ensure the credibility of the analysis and findings, an ELT academician voluntarily became an intercoder for the analysis of the qualitative findings identified during the observations. The inter-rater reliability was calculated based on a simple percentage (Mackey \& Gass, 2016) calculation of $79 \%$. Then, a discussion between the two coders was held to reconcile the items of disagreement and to formulate the final analysis report.

\section{Research Question}

One of the essential communicative skills needed for EFL students is 'speaking', especially in universities and colleges where most courses are delivered in English nowadays. To speak English well, learners need an English- speaking environment to practise the target language. Such a kind of environment, however, is rarely or even cannot be found in non-English-speaking countries outside language classrooms. Here the problem lends itself to be studied. So, creating a semi English-speaking environment inside English language classrooms is supposed to make up for this lack of milieu. Consequently, the problem, this study tries to investigate, can be stated as 'To what extent can EFL teachers' adherence to using English inside classrooms boost university students' speaking fluency?'

\section{Data Collection \& Analysis Tools}

Hereby, the researchers attempted to find one of the available solutions to the problem of the difficulty to fluently speak English that was faced by university students. This is done by exploring the effects of EFL teachers' commitment to using English inside their classes on the oral fluency of adult language learners. For the vignette, 31 university students were assigned. In case studies, most researchers tend to choose from various purposive sampling techniques according to the case to investigate (Creswell, 2007). Participants were recruited, in the present research, purposively on the basis of their speaking performance, which is a non-probability sampling technique (Bryman, 2012; Chawla \& Sondhi, 2014). The tool used to collect data was an observation report based on a checklist whose items covered classroom practices and interactions.

The data obtained were recorded over a period of four weeks. The data were then classified in terms of codes, and they were, later, encoded in the form of percentages for the components of the target skill. Coding yields rich and extensive second language data, entailing looking for and marking found patterns (Mackey \& Gass, 2016). The measures applied in collecting the data were categorized based on a set of created codes. In analysing talk-in-interaction, three types of organization are usually identified: turntaking, sequence organization, and repair (Ellis \& Barkhuizen, 2009). The measures 
used in this study are presented in Table1. Some of the following criteria used for assessing speaking fluency were adapted from Koizumi (2005).

Table 1

Fluency Measures

\begin{tabular}{|c|c|c|c|}
\hline & Theme & Code & Measure \\
\hline \multirow{11}{*}{ 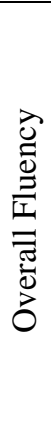 } & Utterances & 1.1 & No. of words per minute \\
\hline & Quality & 1.2 & No. of words per analysis of speech unit (AS-unit) \\
\hline & & 1.3 & No. of clauses per minute \\
\hline & Stress, Rhythm & 2.1 & No. of dysfluency markers per minute \\
\hline & $\&$ & 2.2 & No. of dysfluency markers per word \\
\hline & Intonation & 2.3 & No. of dysfluency markers per AS-unit \\
\hline & & 3.1 & No. of unnatural pauses \\
\hline & Speech Stream & 3.2 & No. of inhibition remarks \\
\hline & & 3.3 & No. of hesitations \\
\hline & & 3.4 & No. of self-corrections \\
\hline & & 3.5 & No. of repetitions \\
\hline
\end{tabular}

Then, thematic analysis was applied to interpret the data gathered. Based on the codes created as in Table 1, four main themes emerged, which are listed below.

-quality of utterances

- stress, rhythm, and intonation

- speech stream

- overall fluency

\section{Delimitation of the Study}

In the case of the transformability or generalisability of the findings of this study, it should be limited to tertiary (university) students, excluding other educational stages. Also, the researchers explored only speaking skill fluency; other skills, however, were not investigated. Finally, the study was restricted to EFL/ESL contexts.

\section{FINDINGS}

The present paper explored how far using English, intended here to be the target language (L2), as the main channel for language classroom communication can scaffold adult learners' oral fluency. The current study follows Nation (1989) in specifying the aspects of fluency. There are three main aspects of oral fluency: 1) the speed and flow of language production; 2) the degree of control of the language items, i.e., pausing, rhythm, pronunciation, and stress; and 3) the way of content interrupting. The data gained in terms of the four themes stated earlier for speaking fluency are analysed in the following.

\section{Quality of Utterances}

For the quality of speakers' utterances, it was scaled thematically in terms of the number 
of words per minute, the number of words per analysis of speech unit, and the number of clauses per minute. Specifically, utterances quality refers to the chunks of the language used; how meaningful, and how close to native-like utterances. Target learners' utterances quality was recorded over a period of four weeks to explore in which direction it was going on. Students' speech was first recorded on the checklist regarding the quality of responses and interaction. Then, the general tendency of the data obtained for the quality of utterances was visualized in terms of improvement percentages, as in Figure 2, according to the week in which they fall.

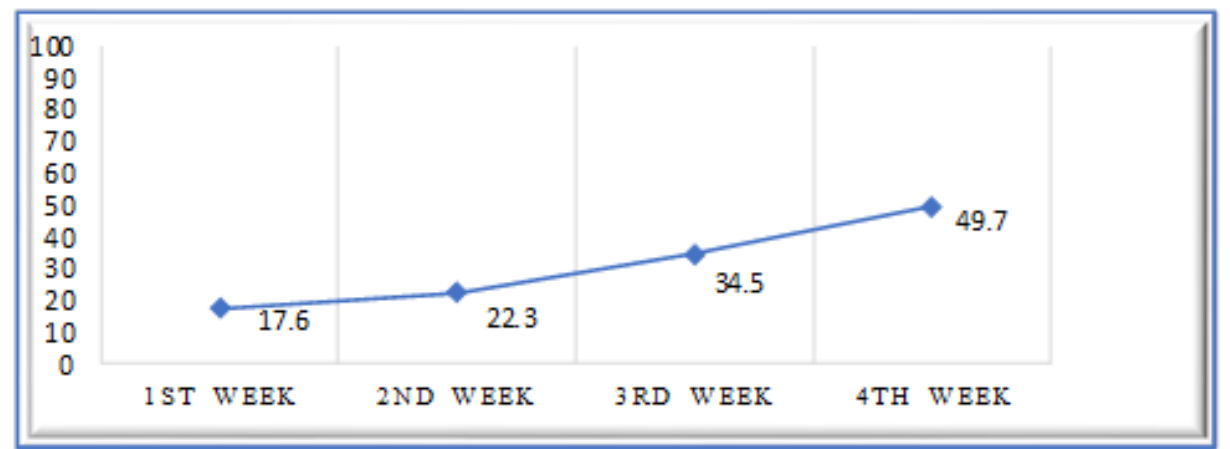

Figure 2

Quality of Utterances

The line graph in Figure 2 presents the data collected in terms of utterances quality over four weeks. As estimated, it was found that students' utterances improved gradually but slowly. It started at a very low level at $17.6 \%$ in the first week. Then, the quality slightly enhanced to $22.3 \%$ in the second week. In the third week, the degree of quality estimated was $34.5 \%$. Finally, a slightly notable enhancement occurred in the quality of learners' utterances scoring $49.7 \%$ in the fourth week.

\section{Stress, Rhythm \& Intonation}

Students' oral fluency was assessed in terms of stress, rhythm, and intonation. This assessment was done based on how natural a speaker was in pronouncing whole sentences, applying smooth linking between words and phrases, as well as the appropriate stress and tones placed on the right syllable for the right word in the right context within a sentence. Further on, their speech was evaluated according to the intonation used, whether falling or rising. Participants' performance was checked regularly over the assigned period of four weeks. The record was kept for every hour, and then the average was computed for the whole week, and afterward, the four weeks performance was evaluated in terms of percentages as a general tendency. 


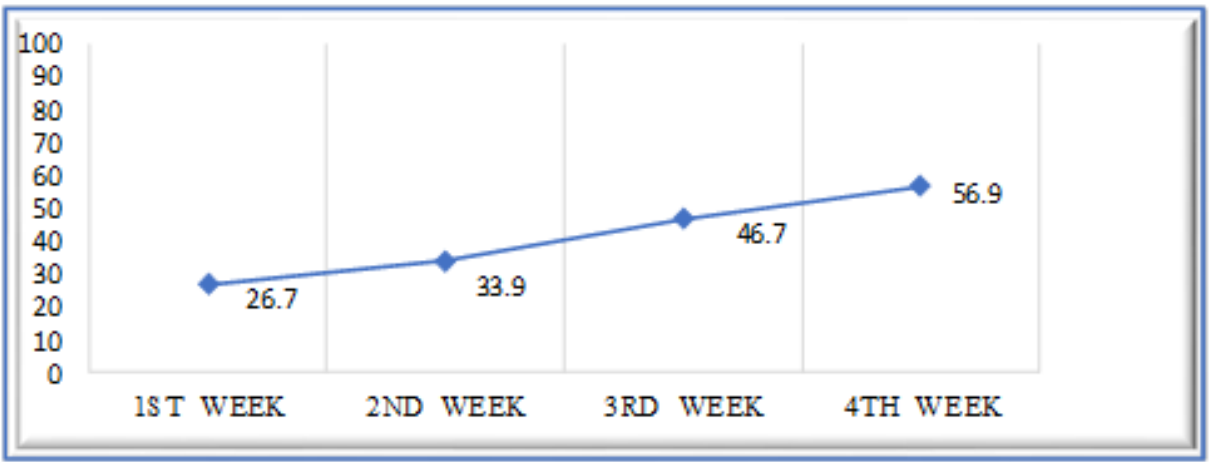

Figure 3

Stress, Rhythm \& Intonation Tendency

As shown in Figure 3, learners' oral outcomes, in terms of stress, rhythm, and intonation, were increasing steadily. This assessment was calculated according to the number of dysfluency markers used per minute, of those per unit, and of those per the analysis of speech unit. While learners' performance was improving, violations of speech intralinguistic features of pronunciation were dropping considerably. In the first week, the performance tendency was assessed for stress, rhythm, and intonation that started at $26.7 \%$, went up to $33.9 \%$ in the second week, was $46.7 \%$ in the third week, and ended up at $56.9 \%$ in the last week.

\section{Speech Stream}

The speech stream level of learners' oral performance was interpreted based on how successfully learners were controlling a set of hindrances to the speech speed and natural flow. This effectiveness of speech stream dwelled in lowering the number of unnatural pauses, of inhibition remarks, of hesitations, of self-corrections, and of repetitions. These qualities were coded and then thematically analysed to encode the qualitative data gathered as graphed in Figure 4.

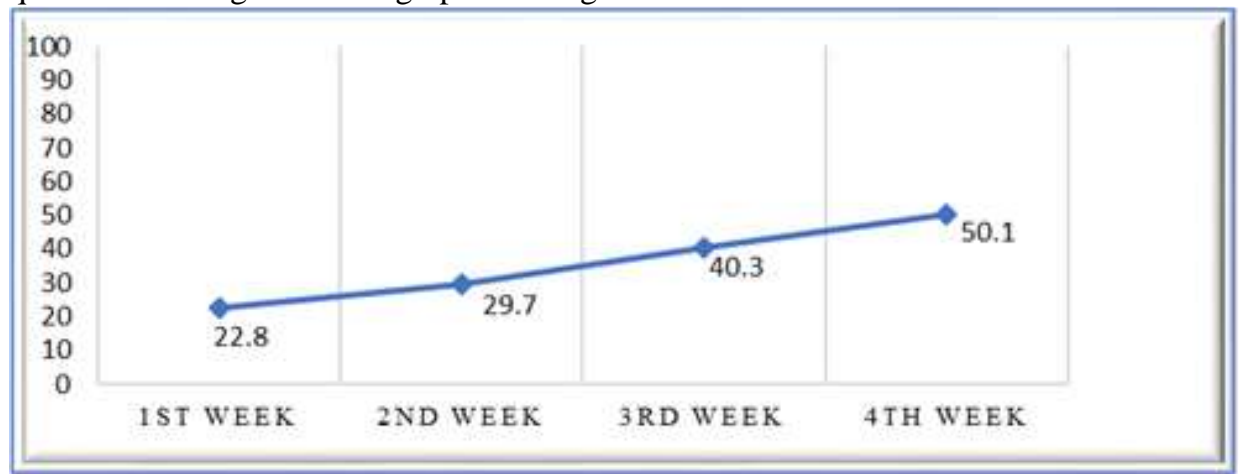

Figure 4

Speech Flow 
The data presented in Figure 4 are based on the percentage of improvement the students could achieve regarding the speed of speech production and natural flow. Learners' performance in this regard started at $22.8 \%$ in the first week, with a little improvement, $29.7 \%$, in the second week, and then it went up steadily at around $10 \%$ in the last two weeks, $40.3 \%$ was achieved in the third week, and 50.1\% was in the last week of the target study duration.

\section{Fluency Overall Progress}

Students' overall speaking progress in terms of fluency was concluded by calculating the average improvement in the previous three themes which was based on the quality of utterances, stress, rhythm and intonation tendency, and speech flow within each week in order to identify the real overall progress that the participants could achieve in terms of oral fluency over the 4-week delivery of language teaching mediating L2. On learners' fulfillment of the previous criteria, a participant was labelled a 'fluent' non-native speaker.

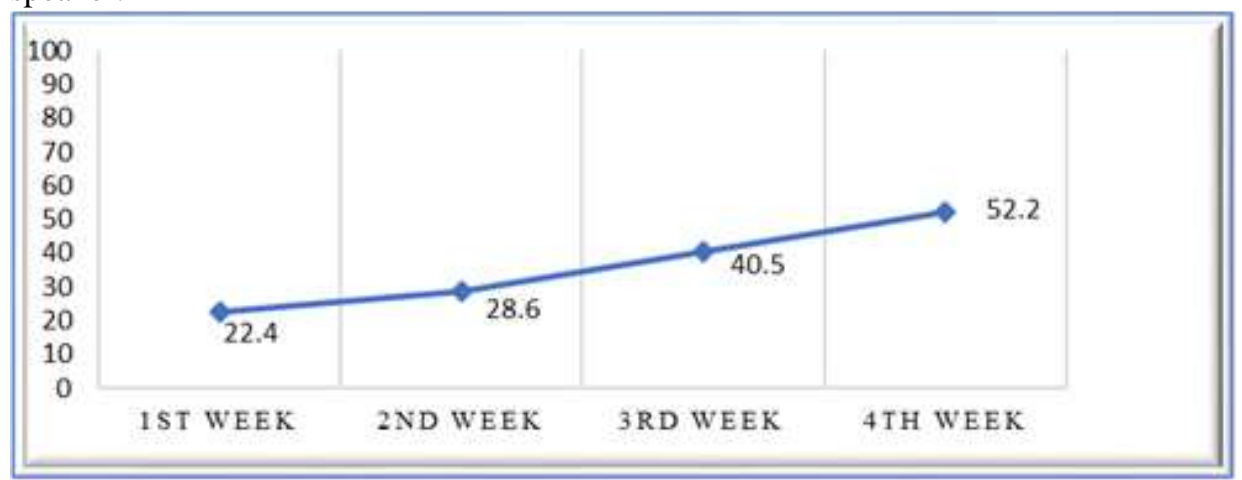

Figure 5

Fluency Overall Progress

Based on the data gleaned, as shown in Figure 5, the real progress of speaking fluency through implementing the target language as the main medium of classroom instruction and interaction shifted gradually and steadily from $22.4 \%$ in week $1,28.6 \%$ in week 2 , $40.5 \%$ in week 3 to $52.2 \%$ in week 4 , the last week.

\section{DISCUSSION}

This research investigated the extent to which EFL teachers' adherence to using English inside classrooms can help students improve their speaking fluency. The main target of all language learners is to speak in the target language; however, learning a second language in educational institutions has traditionally been focused more on listening, reading, and writing aspects than speaking in its spontaneous natural features (Starkey, 2012). The present study findings, in this respect, identified the same problem.

Based on the data gleaned, most of the observed tertiary-level students lack speaking fluency in English. Most teachers do not use sufficient English in class, and most 
classroom practices neglected speaking English as a communicative skill for classroom interaction. Most instruction of all courses is delivered in the native language, instead of the target language, even though the materials were in English; elaboration and discussions, undoubtedly, were mainly native-language based. Most university students depend on their native language to understand English lessons. Few lessons were conducted using the target language fully. During those class sessions in which the instructor used English as the main language of classroom discussion, learners tend to be more active and engaged, and their fluency was much more obvious to detect.

In settings where the teachers tended to have the dominant control of the class, giving themselves the central part of communication, learners were less fluent speakers, having no or limited opportunities to participate orally. This conclusion is consistent with what Wang (2014) concluded. On the contrary, the students were considered more fluent in an environment within which the students were more actively engaged in conversations and classroom discussions. This is in support of the article of faith that claims that teacher-over-talk weakens the learners' participation and their fluency as well.

Based on the data obtained, it was concluded that the students' oral fluency improved gradually over the period of the four weeks, while the third and the fourth weeks witnessed the most remarkable improvement. The assessment of the four themes together reflects that fluency can be fostered over time, but it takes time to reform.

Using English, L2 as a medium of instruction, helped in creating an encouraging environment in which the students can practise speaking in L2. This conclusion is on par with Ellis (2009), who stressed the role of teachers in providing a room for students to communicate and interact in L2 classrooms. Mediating L2 is expected to raise selfesteem among learners when they observe that they are progressing in oral fluency since there is a notable relationship between students' achievement and their self-esteem (Acun, 2020). The ability to participate appropriately in relevant speech events in classroom lessons is central to communicative competence (Mitchell, Myles \& Marsden, 2013). Nonetheless, mediating the target language, despite being effective as uncovered by the results, does not guarantee to master oral fluency by itself; it has to be integrated with other media, aids, and practices.

\section{CONCLUSION}

The present study explored one of the factors expected to contribute to fostering learners' speaking fluency- using the target language as the medium of classroom interaction. Language learners need true practical support, making use of every single effort to help them overcome the factors working as barriers to mastering speaking fluency. Using the target language as a medium of classroom instruction and discussion and giving a conducive atmosphere for student-talk in classrooms were found practical factors for enhancing learners' speaking skills and their motivation in a low-pressure teaching and learning environment. This conclusion comes in line with what stressed by Ellis (2012) that "when anxiety does arise to the use of L2, it seems to be restricted mainly to speaking and listening" (p. 692). More importantly, mediating L2 in ELT helps learners develop language learning autonomy, which is now playing an essential 
role in the language learning field (Orawiwatnakul \& Wichadee, 2017).

Therefore, one of the remedies explored in the present study is the often use of English as the target language in classroom instruction and discussions. Although the rate of improvement is still below expectations as reflected in the findings, mediating L2 was deemed effective, but it can work better with other various techniques and practices if achieving higher scores is the target. Therefore, ELT should be mainly directed to innovating and enriching teaching pedagogy. In conclusion, during the current project that aims at improving learners' oral proficiency, we have found out that there is no super tool that can work well alone for enhancing adult learners' speaking performance. This indicates that the most effective method up to now is varying techniques and practices that ensure a student-centred environment. This is supposed to advocate the eclectic approach in ELT.

\section{REFERENCES}

Abugohar, M. A., Al-Hnifat, M. A., Al-Smadi, O. A., Rashid, R. A., \& Yunus, K. (2019). English language speaking skill issues in an EMP context: Causes and solutions. International Journal of English Linguistics, 9(3), 211-225. https://doi:10.5539/ijel.v9n3p211.

Abugohar, M. A., \& Yunus, K. (2018). Difficulties encountered by Arab students in pronouncing English correctly. International Journal of Education \& Literacy Studies, 6(4), 93-100. https://doi.org/10.7575/aiac.ijels.v.6n.4p.93.

Abugohar, M., Yunus, K., Raba'ah, G., \& Ahmed, T. A. (2019). Integrating cloud world synergy in ELT to adults: Perspectives of handheld technologies. International Journal of Interactive Mobile Technologies, 13(10), 150-168.

Abugohar, M., Yunus, K., \& Rashid, R. A. (2019). Smartphone applications as a teaching technique for enhancing tertiary learners' speaking skills: Perceptions and Practices. International Journal of Emerging Technologies in Learning, 14(9), 74-92. https://doi.org/10.3991/ijet.v14i09.10375.

Acun, I. (2020). The relationship among university students' trust, self-Esteem, satisfaction with life and social media use. International Journal of Instruction, 13(1), 35-52. https://doi.org/10.29333/iji.2020.1313a.

Ahmed, M. (2016). Communicative language teaching: A practical scenario in the context of Bangladesh. Advances in Language and Literary Studies, 7(5), 97-104. https://doi.org/10.7575/aiac.alls.v.7n.5p.97.

Akmajian, A., Demers, R. A., Farmer, A. K., \& Harnish, R. M. (2001). Linguistics: An introduction to language and communication. Cambridge: The MIT Press.

Albahri, M. A., Yang, P., \& Moustakim, M. (2018). Saudi Arabian tertiary teachers' and learners' attitude towards the communicative language teaching (CLT). International Journal of Information and Education Technology, 8(4), 317-321. https://doi.org/10.18178/ijiet.2018.8.4.1055. 
Albino, G. (2017). Improving speaking fluency in a task-based language teaching approach: The case of EFL learners at PUNIV-Cazenga. SAGE Open, 7(2), 1-11. https://doi.org/10.1177/2158244017691077.

Bohlke, D. (2014). Fluency-oriented second language teaching. In M. Celce-Murcia, D. Brinton, \& M. Snow (Eds.), Teaching English as a second or foreign language (pp. 121-135). Boston, MA: National Geographic Learning.

Bryman, A. (2012). Social research methods. Oxford: Oxford University Press.

Chawla, D., \& Sondhi, N. (2014). Research methodology: Concepts and cases. New Delhi, India: VIKAS.

Cook, V. (2006). Using the first language in the classroom. Retrieved from http://homepage.ntlworld.com/vivian.c/Writings/Papers/L1inClass.htm.

Creswell, J. W. (2007). Qualitative inquiry and research design: Choosing among five approaches. Thousand Oaks, CA: Sage.

Dickson, P. (1996). Using the target language: A view from the classroom. Berkshire: The National Foundation for Educational Research.

Dörnyei, Z. (2011). Research methods in applied linguistics. Oxford: Oxford University Press.

Ellis, R. (2009). SLA research and language teaching. Oxford: Oxford University Press.

Ellis, R. (2012). The study of second language acquisition. Oxford: Oxford University Press.

Ellis, R., \& Barkhuizen, G. (2009). Analyzing learner language. Oxford University Press.

Fahad, A. (2012). Enhancing students' communicative skills through classroom interaction in Iraqi EFL classes. Department of English, College of Education, University of Thi Qar, Iraq.

Flick, U. (2014). An introduction to qualitative research. Los Angeles, CA: Sage.

Guilloteaux, M. J. (2008). Three effective classroom managers: A look inside South Korean EFL classrooms. In T. S. C. Farrell (Ed.), Classroom management (pp. 99-110). Alexandria, VA: TESOL.

Hatch, E. (1978). Discourse analysis and second language acquisition. Rowley, MA: New Burry House.

Kadi, R., \& Madini, A. (2019). Causes of Saudi students' unwillingness to communicate in the EFL classrooms. International Journal of English Language Education, 7(1), 5169. https://doi.org/10.5296/ijele.v7i1.14621.

Khati, A. R. (2011). When and why of mother tongue use in English classrooms. Journal of NELTA, 16(1-2), 42-51. https://doi.org/10.3126/nelta.v16i1-2.6128. 
Koizumi, R. (2005). Speaking performance measures of fluency, accuracy, syntactic complexity, and lexical complexity. Japan-Britain Association for English Teaching Journal, 9, 5-33.

Krashen, S. D. (2009). Principles and practice in second language acquisition. Oxford: Pergamon.

Krashen, S. D., \& Terrell, T. D. (1995). The Natural approach \& language acquisition in the language classroom. London: Hall Macmillan.

Lennon, P. (1990). Investigating fluency in EFL: A qualitative approach. Language Learning, 40, 387-417.

Littlewood, W. (1981). Communicative language teaching: An introduction. Cambridge: Cambridge University Press.

Macaro, E. (1997). Target language, collaborative learning and autonomy. Bristol, UK: Multilingual Matters.

Mackey, A., \& Gass, S. M. (2016). Second language research: Methodology and design. New York, NY: Routledge.

Mitchell, R., Myles, F., \& Marsden, E. (2013). Second language learning theories. London: Routledge.

Molina, M., \& Briesmaster, M. (2017). The use of the 3/2/1 technique to foster students' speaking fluency. Inquiry in Education, 9(2), 1-13.

Nation, I. S. P. (1989). Improving speaking fluency. System 17(3), 377-384.

Ohta, A. S. (2009). Rethinking interaction in SLA: Developmentally appropriate assistance in the zone of proximal development and the acquisition of L2 grammar. In J. Lantolf (Ed.), Sociocultural theory and second language learning (pp. 51-78). Oxford: Oxford University Press.

Orawiwatnakul, W., \& Wichadee, S. (2017). An investigation of undergraduate students' beliefs about autonomous language learning. International Journal of Instruction, 10(1), 117-132.

Sherwani, S. H. T., \& Kiliç, M. (2017). Teachers' perspectives of the use of CLT in ELT classrooms: A Case of Soran District of Northern Iraq. Arab World English Journal, 8(3), 191-206. https://doi.org/10.24093/awej/vol8no3.13.

Starkey, L. (2012). Teaching and learning in the digital age. London: Routledge.

Van Lier, L. (1988). The classroom and the language learner. London: Longman.

Vygotsky, L. (1962). Thought and language. Cambridge: MIT Press.

Wang, Z. (2014). Developing accuracy and fluency in spoken English of Chinese EFL learners. English Language Teaching, 7(2), 110-118. 
Wolfe-Quintero, K., Inagaki, S., \& Kim, H.-Y. (1998). Second language development in writing: Measures offluency, accuracy \& complexity. Honolulu, HI: University of Hawaii Press.

Yavari, F., \& Shafiee, S. (2019). Effects of shadowing and tracking on intermediate EFL learners' oral fluency. International Journal of Instruction, 12(1), 869-884. https://doi.org/10.29333/iji.2019.12156a.

Yusof, N., \& Abugohar, M. A. (2017). Teachers' attitudes towards the use of extracurricular activities in enhancing students' speaking skills. International Journal of Academic Research in Progressive Education and Development, 6(3), 153-163. https://doi.org/10.6007/IJARPED/v6-i3/3168. 